\title{
Effects of oil absorption on the wear behaviors of carbon/epoxy woven composites
}

\author{
Jae H. Lee, Jae S. Lee and Kyong Y. Rhee \\ School of Mechanical Engineering, College of Engineering, Kyung Hee University, Yongin 446-701, Korea
}

\author{
Article Info \\ Received 16 May 2011 \\ Accepted 21 June 2011 \\ *Corresponding Author \\ E-mail: rheeky@khu.ac.kr
}

\section{Open Access}

DOI: http://carbonlett.org/

10.5714/CL.2011.12.4.249

This is an Open Access article distributed under the terms of the Creative Commons Attribution Non-Commercial License (http://creativecommons.org/licenses/ by-nc/3.0/) which permits unrestricted non-commercial use, distribution, and reproduction in any medium, provided the original work is properly cited.

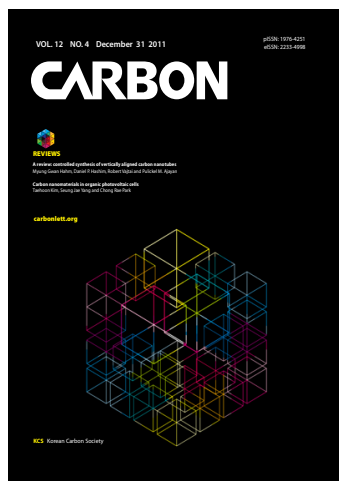

http://carbonlett.org

pISSN: $1976-4251$

elSSN: 2233-4998

Copyright $\odot$ Korean Carbon Society

\begin{abstract}
Carbon/epoxy woven composites are prominent wear-resistant materials due to thestrength, stiffness, and thermal conductivity of carbon fabric. In this study, the effect of oilabsorption on the wearbehaviors of carbon/epoxy woven composites was investigated. Wear tests were performed ondry and fully oil-absorbed carbon/epoxy woven composites. The worn surfaces of the test specimenswere examined via scanning electron microscopy to investigate the wear mechanisms of oil-absorbed carbon/epoxy woven composites. It was found that the oil absorption rate was $0.14 \%$ when the carbon/epoxy woven composites werefully saturated. In addition, the wear properties of the carbon/epoxy woven composites were found to beaffected by oilabsorption. Specifically, the friction coefficients of dry and oil-absorbed carbon/ epoxy woven composites were $0.25-0.30$ and $0.55-0.6$, respectively. The wear loss of the oilabsorbed carbon/epoxy woven composites was $3.52 \times 10^{-2} \mathrm{~cm}^{3}$, while that of the dry carbon/ epoxy woven composites was $3.52 \times 10^{-2} \mathrm{~cm}^{3}$. SEM results revealedthat the higher friction coefficient and wear loss of the oil-absorbed carbon/epoxy woven composites can beattributed tothe existence of brokenand randomly dispersed fibers due to the weak adhesion forces between the carbon fibers and the epoxy matrix.
\end{abstract}

Key words: carbon/epoxy woven composites, friction coefficient, wear volume loss

\section{Introduction}

The use of woven fabric reinforced polymer composites has increased in various industries due to their excellent mechanical properties in both the longitudinal and transverse directions. Among the various reinforced polymer composites, carbon/polymer woven composites are prominent wear-resistant materials because oftheir highstrength, stiffness, and thermal conductivity. However, carbon/polymer woven composites generally suffer from weak adhesion at the carbon/matrix interface due to the hydrophobic properties of carbon fabric. Adhesion between carbon fabric and thepolymer matrix is crucial to the wear properties of carbon/polymer woven composites. As such, a number of studies have been conducted to improve the adhesion strength of carbon fibersin the polymer matrix by modifying the surface properties of carbon fiber [1-6]. Epoxy polymer has outstanding stiffness, dimensional stability, and chemical resistance. However, only a few studies have been performedto investigate the wear properties of carbon/epoxywoven composites [7,8]. In particular, research on the wear behaviors of oil-absorbed carbon/epoxy woven composites has yet to be reported.

In the present study, the effects of oilabsorption on the wearbehaviors of carbon/epoxy woven compositeswereinvestigated. Ball-on-disk wear tests were performed using dry and fully oil-absorbed carbon/epoxy woven composites. After the wear tests, the worn surfaces of the dry and fully oil-absorbed carbon/epoxy woven compositeswereanalyzedvia scanning electron microscopy(SEM).

The materials used in this work were carbon plain-woven fabric (CF332NON, Repub- 


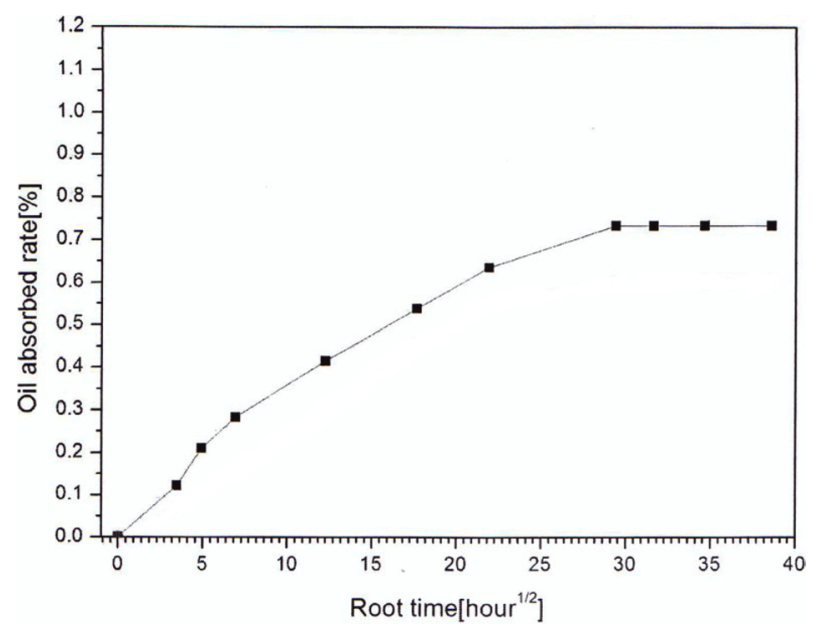

Fig. 1. Oil absorption rate for carbon/epoxy woven composites as a function of immersion time.

lic of Korea Carbon, Korea), bisphenol-A type epoxy (YD-115, Kukdo Chemical, Korea), and D-230 hardener (Dianiline, Kukdo Chemical). The epoxy resin and hardener were mixed in a 6:4 ratio by weight percent. Four-plied carbon/epoxy woven composites with fiber content of less than $67 \%$ by weight were used to fabricate the wear specimens. The carbon/epoxy woven composites were cured in an autoclave under a pressure of $2 \mathrm{kgf} / \mathrm{cm}^{2}$ at $130^{\circ} \mathrm{C}$ for $6 \mathrm{~h}$. A diamond wheel cutter was used to cut the cured composites into $30 \mathrm{~mm} \times 30 \mathrm{~mm}$ pieces. The wear specimens were immersed in automobile oil (SK Chemical, Korea) until they were fully saturated. Ball-on-disk wear tests, where one zirconia $\left(\mathrm{ZrO}_{2}\right)$ ball was employed, were conducted at room temperature using a Neotribo Friction andWear test machine (Neo-Plus, Korea). The applied vertical load and rotational speed were $19.6 \mathrm{~N}$ and $10.6 \mathrm{~m} / \mathrm{min}$, respectively. The sectional shape of the wear track was measured with a surface profiler (Dektak 150 , Veeco Ltd., USA) so as to determine the wear volume loss.

The oil contentsinthe carbon/epoxy woven composites (C)werecalculated from the specimen weights before and after oil absorption:

$$
C=\frac{W_{w}-W_{d}}{W_{d}} \times 100 \%,
$$

where $\mathrm{W}_{\mathrm{w}}$ and $\mathrm{W}_{\mathrm{d}}$ represent the weights of oil-absorbed and dry specimens, respectively. Theoil contentsofthe carbon/epoxy woven composites are shown in Fig. 1 as a function of the immersion time. The oil absorptionvalues were in good agreementwith the dual-stage Fickian model,which states that oil absorption follows a linear curve before the saturation point and then gradually reaches a fully saturated stage. Carbon/epoxy woven compositeswere fully saturated after 36 days, at which point the oil absorption rate was $0.14 \%$.

The effects of oil absorption on the wear behaviors of carbon/epoxy woven composites wereinvestigated by determining changes in the friction coefficient as a function of the wear distance. The changes in the friction coefficient as a function of the wear distance for dry and oil-absorbed carbon/epoxy woven compositesare shown in Fig. 2. The oil-absorbed carbon/epoxy woven composites had a higher friction coefficient when compared to thedry carbon/epoxy woven composites. Specifically,
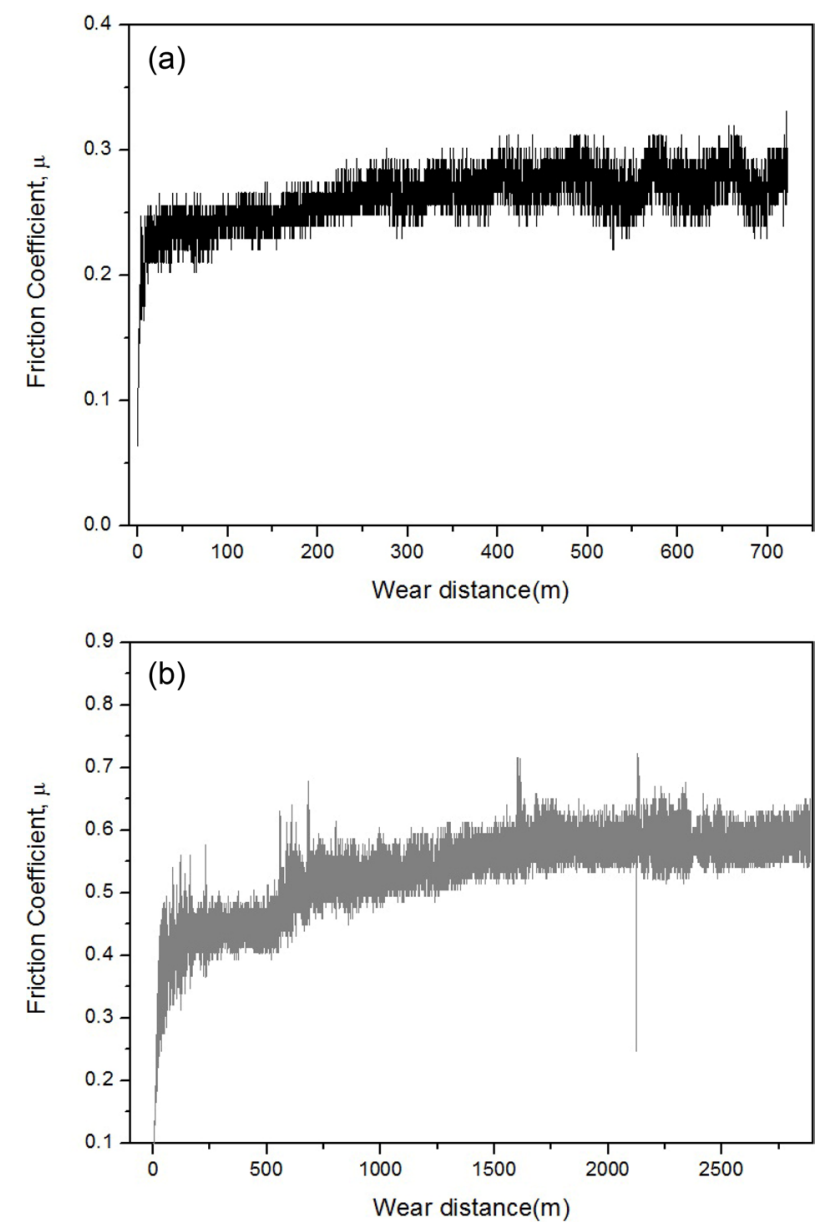

Fig. 2. Variation of friction coefficient as a function of wear distance:(a) dry and (b)oil-absorbed carbon/epoxy woven composites.

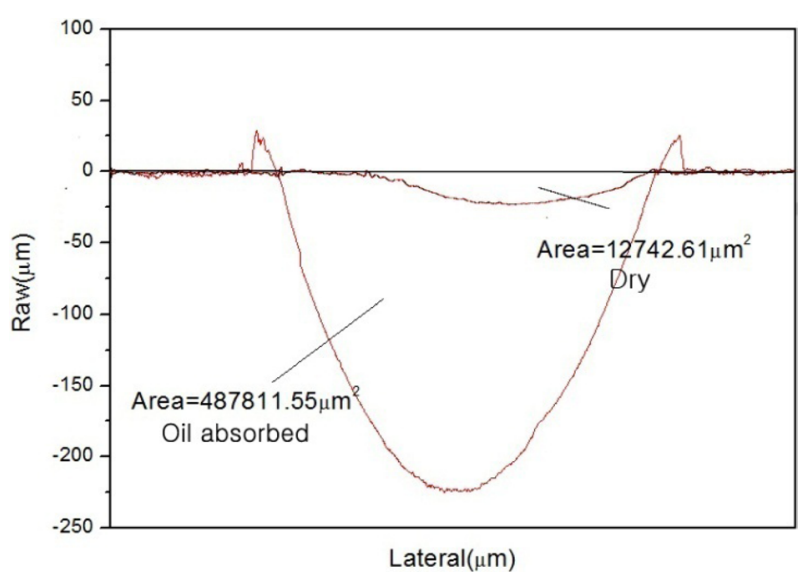

Fig. 3. Surface profilers of worn surfaces for carbon/epoxy woven composites.

the friction coefficients of dry and oil-absorbed carbon/epoxy woven composites were $0.25-0.30$ and $0.55-0.6$, respectively.

A comparison of the wear-depth profiles for dry and oil-absorbed carbon/epoxy woven composites is shown in Fig. 3. As 


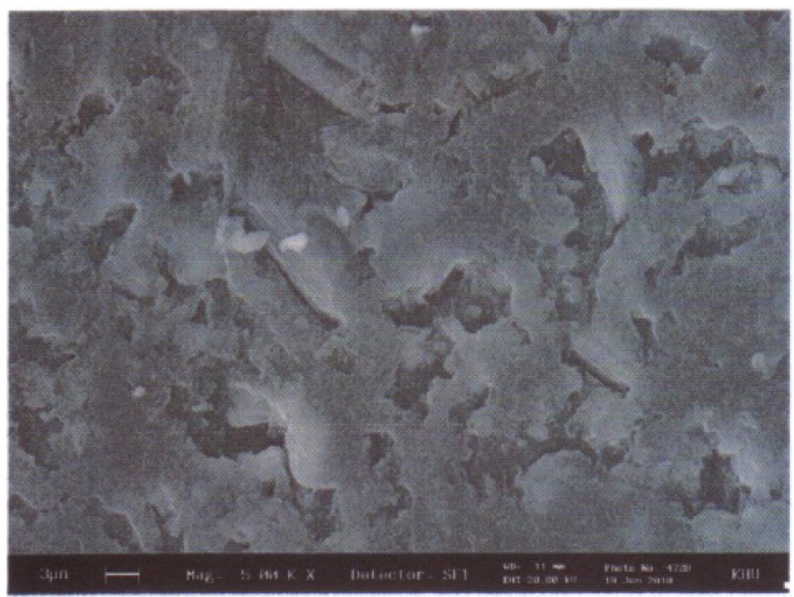

(a)

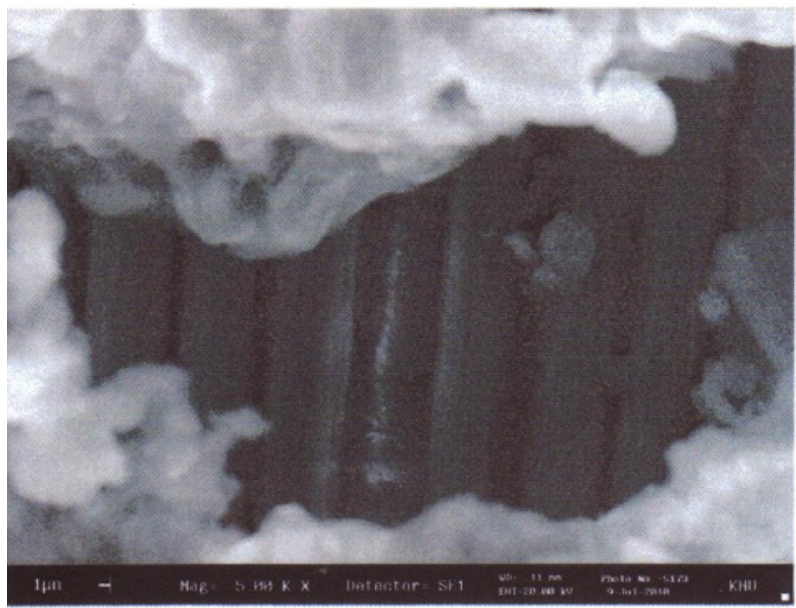

(b)

Fig. 4. Worn surfaces of (a) dry and (b) oil-absorbed carbon/epoxy woven composites.

expected from the change in the friction coefficient, the oil-absorbed carbon/epoxy woven composites exhibited worse wearresistant behavior than the dry carbon/epoxy woven composites. The maximum depth profiles of dry and oil-absorbed carbon/ epoxy composites were $23 \mu \mathrm{m}$ and $223 \mu \mathrm{m}$, respectively. The wear volume loss of both composites was calculated based on the wear-depth profile. The wear volume losses of dry and oilabsorbed carbon/epoxy woven composites were $9.20 \times 10^{-4} \mathrm{~cm}^{3}$ and $3.52 \times 10^{-2} \mathrm{~cm}^{3}$, respectively.

The worn surfaces of thedry and oil-absorbed carbon/epoxy woven composites were examined via SEM. A comparison of the worn surfaces of both carbon/epoxy woven composites is shown in Fig. 4. As evident in the figure, abrasive wear occurred for both composites. Fibers were broken and randomly dispersed in the epoxy matrix for the dry carbon/epoxy woven composites.
These fibers were peeled off from the epoxy, and their surfaces were found to be relatively clean. The existence of peeled fibers was due to the weak adhesion forces between the carbon fibers and the epoxy matrix. Such weak adhesion forcesoriginate from the swallowing effect of the epoxy matrix.

In conclusion,the wear properties of carbon/epoxy woven composites were adversely affected by oilabsorption. The friction coefficients and wear losses of oil-absorbed carbon/epoxy woven composites were higher than those of dry carbon/epoxy woven composites. The higher friction coefficients and wear losses of the oil-absorbed carbon/epoxy woven composites are attributed to the weak adhesion forces between the carbon fibers and the epoxy matrix.

\section{Acknowledgements}

This research was supported byBasic Science Research Programthrough the National Research Foundation of Korea (NRF) fundedby the Ministry of Education, Science and Technology (2010-0023106).

\section{References}

[1] Shi Y, Feng X, Wang H, Lu X. The effect of surface modification on the friction and wear behavior of carbon nanofiber-filled PTFE composites. Wear, 264, 934 (2008). http://dx.doi.org/10.1016/j. wear.2007.06.014.

[2] Shi Y, Feng X, Wang H, Lu X. Tribological properties of PTFE composites filled with surface-treated carbon fiber. J Mater Sci, 42, 8465 (2007). http://dx.doi.org/10.1007/s10853-007-1767-7.

[3] Brandl W, Marginean G, Chirila V, Warschewski W. Production and characterisation of vapour grown carbon fiber/polypropylene composites. Carbon, 42, 5 (2004). http://dx.doi.org/10.1016/j.carbon.2003.09.012.

[4] Xu Y, Chung DDL. Silane-treated carbon fiber for reinforcing cement. Carbon, 39, 1995 (2001). http://dx.doi.org/10.1016/s00086223(01)00028-8.

[5] D.D E. The effect of processing on the structure and properties of carbon fibers. Carbon, 36, 345 (1998). http://dx.doi.org/10.1016/ s0008-6223(97)00185-1.

[6] Pittman CU Jr, Jiang W, Yue ZR, Gardner S, Wang L, Toghiani H, Leon y Leon CA. Surface properties of electrochemically oxidized carbon fibers. Carbon, 37, 1797 (1999). http://dx.doi.org/10.1016/ s0008-6223(99)00048-2.

[7] Hosur MV, Vaidya UK, Ulven C, Jeelani S. Performance of stitched/unstitched woven carbon/epoxy composites under high velocity impact loading. Compos Struct, 64, 455 (2004). http:// dx.doi.org/10.1016/j.compstruct.2003.09.046.

[8] Frassine R, Pavan A. The combined effects of curing and environmental exposure on fracture properties of woven carbon/epoxy laminates. Compos SciTechnol, 51, 495 (1994). http://dx.doi. org/10.1016/0266-3538(94)90082-5. 